\title{
Unsteadiness of bivalve clam jet flow according to environmental conditions
}

\author{
S. K. Delavan ${ }^{1,2, *}$, D. R. Webster ${ }^{1}$ \\ ${ }^{1}$ School of Civil and Environmental Engineering, Georgia Institute of Technology, Atlanta, Georgia 30332-0355, USA \\ ${ }^{2}$ Present address: Department of Civil and Natural Resources Engineering, University of Canterbury, Christchurch 8140, \\ New Zealand
}

\begin{abstract}
To determine whether hard clams Mercenaria mercenaria alter excurrent jet velocity as a function of environmental factors, this laboratory study quantified the excurrent jet velocity as a function of bulk mean crossflow velocity, density of clam patch, and clam size. The excurrent velocity was measured via the non-intrusive particle image velocimetry technique. The flow and unsteady patterns in the time records of vertical velocity near the tip of the excurrent siphon were analyzed by calculating the mean, variance, power spectral density, fractal dimension, lacunarity, and mean jet-to-crossflow ratio. The results revealed that clams vary their excurrent flow characteristics according to bulk mean crossflow velocity; in particular, the texture of the time record of velocity varied. Further, the jet-to-crossflow velocity ratio was larger for smaller clams, and the response of clams to the density of the clam patch was dependent on the size of the animal. These observed behaviors may impact the predation success of blue crabs Callinectes sapidus and knobbed whelks Busycon carica under various environmental conditions. In this context, the results indicated that blue crabs dominate the predator-prey system because of the dependence on clam size and bulk mean crossflow velocity. Alternatively, the varying clam excurrent siphon velocity behavior may provide hydrodynamic signaling of the clam patch recruitment status to settling larvae.
\end{abstract}

KEY WORDS: Predator-prey $\cdot$ Olfactory predation $\cdot$ Jets-in-crossflow $\cdot$ Bivalve $\cdot$ Non-consumptive predator effects $\cdot$ Lacunarity

Resale or republication not permitted without written consent of the publisher

\section{INTRODUCTION}

The predator-prey relationships between bivalve clams Mercenaria mercenaria and predators such as blue crabs Callinectes sapidus and knobbed whelks Busycon carica are influenced by the filter-feeding behavior of clams (Smee \& Weissburg 2006). As the water passes through the filter-feeding clam, waste metabolites are picked up and carried out through the excurrent siphon in a jet-like flow. The released metabolites are transported downstream with the ambient flow and create the chemical plume that may be tracked by predators. This predator-prey interaction is mediated by 3 distinct phases: generation of the chemical signal, transport of the chemical downstream, and acquisition of the chemical information. Much of the current literature on this predator-prey relationship is focused on the acquisition of the chemical signal and the behavioral reaction by the predator (e.g. Weissburg \& Zimmer-Faust 1993, Jackson et al. 2007, Page et al. 2011a,b). In contrast, the goal of the current study was to quantify the excurrent siphon flow of the bivalve clam M. mercenaria. In particular, this study took an important step toward understanding how the excurrent jet velocity behavior was modified by environmental conditions.

We focused on the variation of the excurrent flow of hard clams in response to several environmental parameters, including bulk mean crossflow velocity, density of clam patch, and size of the clam. The char- 
acteristics of the excurrent flow as a function of bulk mean crossflow velocity and clam size are of interest because the predators of this system, blue crabs and knobbed whelks, both consume clams and use olfactory navigation as a means of locating prey, but the turbulence regimes in which they are successful are highly disparate. Blue crabs are less successful predators during highly turbulent hydrodynamic conditions (Jackson et al. 2007). In contrast, knobbed whelks are successful in highly turbulent regimes (Ferner \& Weissburg 2005). Also, blue crabs prefer clams of a small size range despite the fact that they can consume prey over a wide size range (Micheli 1995). Therefore, as clams increase in size, they become less susceptible to predation by blue crabs while maintaining their susceptibility to whelk predation. Thus, there may be alternate strategies for predator avoidance depending on the size of the clams and the turbulence regime of the environment in which they live.

The influence of the density of the clam patch was also of interest because there may be predator avoidance strategies depending on the proximity of conspecifics. High-density patches may appear as one large, hard to eat prey to blue crabs, and small clams may have higher survival rates in these patches. Also, greater density could mean that loss of only a few clams out of the group minimally influences the overall population. Alternatively, juveniles may be at greater risk when settling in established clam beds. Greater clam densities may release a larger flux of odorant and, therefore, be more attractive to potential predators. In this context, there may be an advantage to large nearest neighbor distances to decrease the odorant release flux.

It was also relevant to consider clam excurrent flow as a jet-in-crossflow), defined as a jet of fluid exiting an orifice in a direction perpendicular to the direction of the surrounding fluid motion that typically consists of a boundary layer flow along the solid surface containing the orifice, and to quantify the jet velocity characteristics within the context of previous jet-in-crossflow studies. Monismith et al. (1990) and Crimaldi et al. (2007) found that clam mimic jets altered the momentum distribution in the boundary layer in a manner similar to that seen in jetin-crossflow studies (e.g. Andreopoulos \& Rodi 1984). O'Riordan (1993) and van Duren et al. (2006) found similar boundary layer alterations with actual clam and mussel excurrent jets, respectively, in a laboratory setting. Over a wide range of jet and boundary layer Reynolds numbers, the jet-to-crossflow velocity ratio was the dominant indicator of the jet/crossflow interaction (Andreopoulos \& Rodi 1984, Morton \& Ibbetson 1996, Sau \& Mahesh 2008). Hence, we sought to quantify the jet-to-crossflow velocity ratio for the clam excurrent siphon as a function of environmental parameters.

The overall objective of this study was to quantify the clam excurrent jet vertical velocity unsteadiness according to external environmental cues. Laboratory flume experiments captured time records of clam jet vertical velocity for 4 bulk mean crossflow velocity values, 2 clam size ranges, and 2 clam nearest neighbor distances.

\section{MATERIALS AND METHODS}

\section{Animal collection and storage}

Clams that were imported from Florida were purchased from a local supplier near Atlanta, Georgia, USA. Clams were housed in an aquarium filled with artificial sea water with salinity between 28 and 35 ppt. Sand covered the bottom of the aquarium to allow clams to acclimate to laboratory conditions and bury themselves. The aquarium temperature was maintained at room temperature (roughly $22^{\circ} \mathrm{C}$ ), and the $\mathrm{pH}$ was $\sim 8.0$. Clams were fed every other day during data collection periods with a commercially available slurry of live phytoplankton (DT's Live Marine Phytoplankton) purchased from local aquarium/pet stores.

\section{Flow facility}

The flow facility was an artificial seawater flume located in the Environmental Fluid Mechanics Laboratory at the Georgia Institute of Technology (Fig. 1). This biological-grade flume was $0.76 \mathrm{~m}$ wide and $13.5 \mathrm{~m}$ long with a level bed. The bed was covered with a thin layer of sand with a median grain diameter of $d_{50}=1.1 \mathrm{~mm}$. The side walls of the flume were constructed of acrylic for optical transparency. A centrifugal pump recirculated artificial seawater through the flume. The flow depth was controlled by the height of a downstream sharp-edged weir, and the flow rate was calculated via the KindsvaterCarter equation for rectangular weirs (Kindsvater \& Carter 1957). The roughness Reynolds number ( $\operatorname{Re}^{*}$ $=k_{s} u^{*} / v$ ), where $\mathrm{k}_{\mathrm{s}}$ is the effective sand roughness height, $u^{*}$ is the wall shear velocity, and $v$ is the fluid viscosity, was less than 10 for each flow rate used here. 


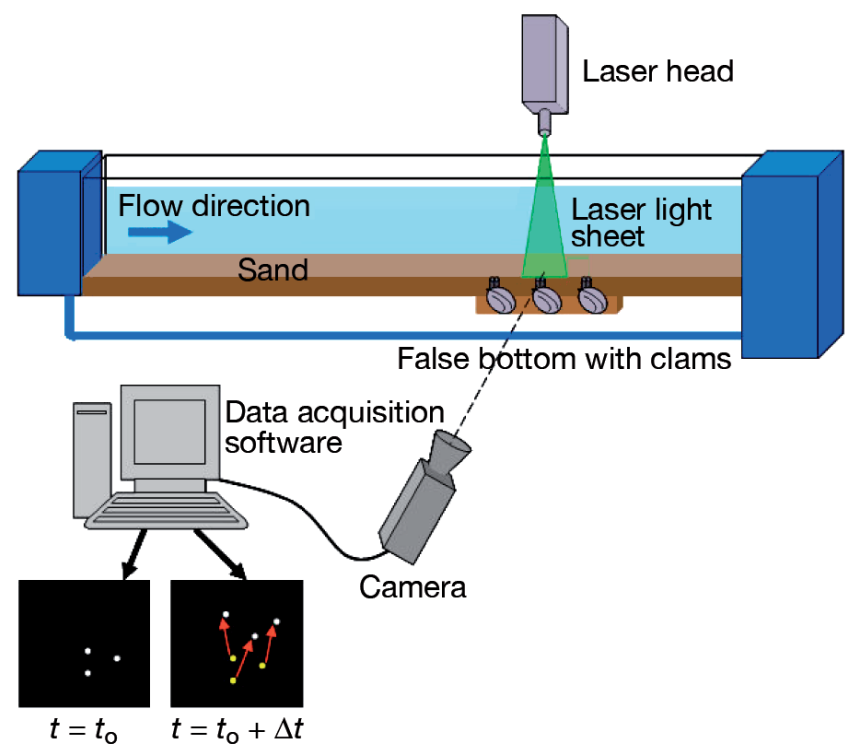

Fig. 1. Schematic of the laboratory seawater flume and setup for the particle image velocimetry (PIV) system. Clams buried in sand sediment in a false bottom section that was $7.8 \mathrm{~cm}$ deep, whereas the sediment in the majority of the flume bed was $2.9 \mathrm{~cm}$ deep. The Nd:YAG laser was located above the flume and was pointed downward. The PIV camera was located beside the flume and viewed the measurement section through the acrylic side wall. $t=$ time

The test section was located $6.2 \mathrm{~m}$ downstream of the flume entrance. A $7.8 \mathrm{~cm}$ (deep) by $45.7 \mathrm{~cm}$ (wide) by $118.7 \mathrm{~cm}$ (long) false bottom section filled with sand was located in the center of the test section, and the sand depth for the remainder of the flume was $2.9 \mathrm{~cm}$. The false bottom section allowed for clams to bury themselves within the sediment and feed naturally.

\section{Velocity measurements}

PIV equipment

Particle image velocimetry (PIV) was used to quantify the clam excurrent velocity. PIV is a non-intrusive means of determining planar velocity fields in moving fluids. This method uses a laser sheet to illuminate tiny seeding particles in a plane while a camera captures images of the particles (Fig. 1). Sequential PIV images are used to determine the particle displacement and velocity in the illuminated plane. Previously, the PIV technique has been used to determine the flow fields around organisms and their appendages (e.g. Mead \& Koehl 2000, Catton et al. 2007, Peng et al. 2007).
The laser was a double head Solo III manufactured by New Wave Research with a wavelength of $532 \mathrm{~nm}, 50 \mathrm{~mJ}$ of energy per laser pulse, and an exiting beam diameter of $4 \mathrm{~mm}$. The beam passed through a system of lenses that form a planar laser sheet (specifically, a symmetrical convex lens of $0.5 \mathrm{~m}$ focal length and a planar-concave cylindrical lens with a $19 \mathrm{~mm}$ focal length). The laser was mounted above the flume, and the laser sheet passed through the fluid surface of the flume above the excurrent siphons of the feeding bivalves (Fig. 1). The water surface was smooth and temporally constant, which led to minimal variation of light transmittance.

Particles of titanium dioxide $(<5 \mu \mathrm{m}$ diameter $)$ were suspended in the fluid, moved with the flow, and were illuminated in the laser sheet. Many types of seeding particles were tested to determine which would be most useful in these experiments. Clams are filter feeders and remove particles from the flow of certain size ranges and organic content (Troost et al. 2009). The following types of seeding particles were tested in this study: corn starch, kaolin, titanium dioxide, and several types of glass balls. Titanium dioxide particles resulted in a good balance between the number of particles passing through the clam and suitable reflection of the laser light for camera visualization. Titanium dioxide was also used by Frank et al. (2008) in their clam jet PIV experiments, and the particles did not appear to influence the clam behaviorally.

Images of the illuminated particles were captured on a monochrome Kodak Megaplus camera (model ES 1.0) with a dual channel 8-bit digital output and a charged coupled device (CCD) sensor array. The camera used a Nikon MicroNikkor lens with a 60 $\mathrm{mm}$ focal length. Both the laser and camera were triggered by a precision pulse generator (Berkeley Nucleonics model 500D). The delay between images in each pair was $10 \mathrm{~ms}$, and image pairs were captured at a frequency of $10 \mathrm{~Hz}$. An individual image required roughly $1 \mathrm{Mb}$ of hard drive space and the images were stored on a hard drive array using Video Savant software (IO Industries). A typical image sequence file used roughly $4.6 \mathrm{~Gb}$ of storage depending on the number of images collected. An error propagation analysis was completed and the uncertainty in the velocity measurements was estimated as $1.0 \mathrm{~mm} \mathrm{~s}^{-1}$, which was roughly $2 \%$ of the measured mean velocity values. Since velocity fluctuations are on the same order as the mean values, the uncertainty in the velocity measurements was quite small. 


\section{PIV analysis}

The PIV algorithm determined the fluid velocity at discrete points in the images and was written by Dasi (2004) based on several earlier PIV algorithms including those by Gui \& Wereley (2002) and Wereley \& Meinhart (2001). Details of the algorithm are provided by Dasi (2004) and are summarized here. First, a background image file was created for the even and odd images of the pairs. The background image was subtracted from the individual images in order to increase the contrast of the particles. The images were then spatially divided into $32 \times 32$ pixel interrogation bins, and a cross-correlation analysis was performed between the first and second image in the pair. A Gaussian peak fit analysis was performed on the cross-correlation data to determine the displacement vector between images. In a second pass, the interrogation bins in the first and second image were shifted by half of the displacement estimate backwards and forwards, respectively, to 'center' the interrogation bin region in the individual image. The correlation analysis was repeated and a new estimate of the displacement vector was calculated. The centering process was repeated until the interrogation bin position correction was less than 0.005 pixels. The displacement vectors were then divided by the delay period between laser pulses (10 ms) to yield the velocity vector. The velocity fields created by the cross-correlation analysis contained a few bad vectors associated with the edges of the image or noise. The bad vectors were removed via a temporal filtering procedure. The filter assumes a Gaussian distribution for the magnitudes of the velocity vectors and removes samples that had a deviation greater than the threshold deviation (typically 3 to 4 times the standard deviation). The filter procedure was repeated until the stray vectors were removed.

\section{Data collection procedure}

Clams of the desired size range were placed on the sediment of the flume false bottom section with desired nearest neighbor distances and allowed to bury themselves under low flow conditions. The clam behavioral response to the laser light was minimal (based on $>50 \mathrm{~h}$ of laboratory observations), which also agreed with the observations of Frank et al. (2008). For an individual clam (see numbered clams in Table 1), data were collected for $225 \mathrm{~s}$ for a randomly chosen bulk mean crossflow velocity value.
Table 1. Mercenaria mercenaria. Mean \pm SD of the vertical velocity $\left(v, \mathrm{~mm} \mathrm{~s}^{-1}\right)$ in the clam excurrent jet. The table reports data for varying nearest neighbor distance (NND), non-dimensional NND ( ${ }^{\text {nd } N N D), ~ b u l k ~ m e a n ~ c r o s s-~}$ flow velocity $\left(U, \mathrm{~cm} \mathrm{~s}^{-1}\right)$, and clam size class

\begin{tabular}{|c|c|c|c|c|}
\hline \multirow[t]{2}{*}{ Clam } & \multirow{2}{*}{$\begin{array}{l}\text { Length } \\
(\mathrm{cm})\end{array}$} & \multirow{2}{*}{$\begin{array}{c}U \\
\left(\mathrm{~cm} \mathrm{~s}^{-1}\right)\end{array}$} & \multicolumn{2}{|c|}{$-v\left(\mathrm{~mm} \mathrm{~s}^{-1}\right)$} \\
\hline & & & $\begin{array}{c}\mathrm{NND}=3 \mathrm{~cm} \\
{ }^{\mathrm{nd}} \mathrm{NND}=0.62\end{array}$ & $\begin{array}{c}\mathrm{NND}=9 \mathrm{~cm} \\
{ }^{\mathrm{nd} N N D}=1.85\end{array}$ \\
\hline \multirow[t]{4}{*}{1} & 4.7 & 0.55 & $3.19 \pm 3.49$ & $3.11 \pm 2.33$ \\
\hline & & 1.20 & $4.50 \pm 8.27$ & $3.57 \pm 3.95$ \\
\hline & & 1.98 & $5.65 \pm 3.67$ & $8.20 \pm 8.45$ \\
\hline & & 2.86 & $2.15 \pm 3.65$ & $2.83 \pm 2.03$ \\
\hline \multirow[t]{4}{*}{2} & 5.2 & 0.55 & $4.15 \pm 3.78$ & $10.46 \pm 5.48$ \\
\hline & & 1.20 & $0.89 \pm 0.93$ & $4.48 \pm 7.01$ \\
\hline & & 1.98 & $0.79 \pm 1.33$ & $4.62 \pm 2.69$ \\
\hline & & 2.86 & $1.68 \pm 5.46$ & $3.30 \pm 7.53$ \\
\hline \multirow[t]{4}{*}{3} & 4.9 & 0.55 & $1.99 \pm 2.15$ & $5.23 \pm 5.36$ \\
\hline & & 1.20 & $4.39 \pm 2.81$ & $1.62 \pm 2.64$ \\
\hline & & 1.98 & $1.79 \pm 1.35$ & $0.64 \pm 4.75$ \\
\hline & & 2.86 & $1.62 \pm 2.09$ & $1.31 \pm 2.55$ \\
\hline \multirow[t]{4}{*}{4} & 4.6 & 0.55 & $4.88 \pm 2.73$ & $3.65 \pm 4.44$ \\
\hline & & 1.20 & $6.97 \pm 2.94$ & $8.05 \pm 11.35$ \\
\hline & & 1.98 & $2.56 \pm 1.92$ & $4.11 \pm 6.55$ \\
\hline & & 2.86 & $2.55 \pm 2.22$ & $0.36 \pm 1.81$ \\
\hline \multirow[t]{4}{*}{5} & 4.9 & 0.55 & $7.65 \pm 3.78$ & $3.26 \pm 1.75$ \\
\hline & & 1.20 & $2.45 \pm 4.19$ & $3.08 \pm 4.41$ \\
\hline & & 1.98 & $2.04 \pm 2.74$ & $2.98 \pm 2.12$ \\
\hline & & 2.86 & $0.52 \pm 1.84$ & $2.63 \pm 2.09$ \\
\hline \multirow[t]{2}{*}{ Clam } & Length & $U$ & $\longrightarrow v(\mathrm{~m}$ & $\left(\mathrm{s}^{-1}\right) \longrightarrow$ \\
\hline & $(\mathrm{cm})$ & $\left(\mathrm{cm} \mathrm{s}^{-1}\right)$ & $\begin{array}{c}\mathrm{NND}=3 \mathrm{~cm} \\
\text { nd NND }=0.41\end{array}$ & $\begin{array}{c}\mathrm{NND}=9 \mathrm{~cm} \\
\mathrm{nd}^{\mathrm{N} N D}=1.23\end{array}$ \\
\hline \multirow[t]{4}{*}{6} & 7.3 & 0.55 & $2.33 \pm 1.22$ & $1.58 \pm 1.67$ \\
\hline & & 1.20 & $0.80 \pm 1.16$ & $1.66 \pm 2.13$ \\
\hline & & 1.98 & $1.47 \pm 2.08$ & $2.12 \pm 3.39$ \\
\hline & & 2.86 & $0.90 \pm 2.01$ & $4.70 \pm 6.19$ \\
\hline \multirow[t]{4}{*}{7} & 7.5 & 0.55 & $3.83 \pm 3.69$ & $2.61 \pm 3.54$ \\
\hline & & 1.20 & $3.33 \pm 2.36$ & $2.34 \pm 3.15$ \\
\hline & & 1.98 & $4.20 \pm 7.43$ & $0.99 \pm 2.20$ \\
\hline & & 2.86 & $3.17 \pm 10.64$ & $2.06 \pm 3.66$ \\
\hline \multirow[t]{4}{*}{8} & 6.9 & 0.55 & $3.26 \pm 2.81$ & $1.83 \pm 9.69$ \\
\hline & & 1.20 & $4.95 \pm 11.63$ & $2.61 \pm 2.52$ \\
\hline & & 1.98 & $5.83 \pm 2.14$ & $1.90 \pm 10.85$ \\
\hline & & 2.86 & $6.19 \pm 7.13$ & $5.40 \pm 5.60$ \\
\hline \multirow[t]{4}{*}{9} & 8.6 & 0.55 & $1.94 \pm 2.25$ & $5.20 \pm 2.46$ \\
\hline & & 1.20 & $2.09 \pm 1.84$ & $3.24 \pm 4.23$ \\
\hline & & 1.98 & $3.17 \pm 1.51$ & $1.65 \pm 3.08$ \\
\hline & & 2.86 & $5.17 \pm 5.27$ & $1.12 \pm 4.16$ \\
\hline
\end{tabular}

The bulk mean velocity in the flume was changed to another randomly chosen target velocity value after the first data collection was complete. This was repeated until the organism had experienced all targeted bulk mean crossflow velocity values. During collection, events such as siphon movement and organism interference were noted so that those events 
could be removed from the time record analysis. Note that suspended food particles were not introduced into the flume because clams were observed to initiate pumping in response to a moving crosscurrent.

\section{Clam size and nearest neighbor distance}

The experimental parameters and the individual clams that were used are given in Table 1. PIV images were collected for a plane that bisected the clam excurrent siphon for clams of 2 size ranges, $4.86 \pm 0.22 \mathrm{~cm}$ and $7.32 \pm 0.32 \mathrm{~cm}$, clam plots with 2 nearest neighbor distances, 3 and $9 \mathrm{~cm}$, and 4 bulk mean crossflow velocity values, $0.55,1.2,1.98$, and $2.86 \mathrm{~cm} \mathrm{~s}^{-1}$. The selected nearest neighbor distances were consistent with those observed in the field, and in addition there was evidence of differences in clam repositioning behavior for nearest neighbor distances in this range (Wilson 2011). Clams may alter their pumping behavior according to their proximity to other clams because of the potential for refiltration of fluid or the additive predation potential with the downstream chemical plume. Also, juvenile or small clams have greater predation pressure from blue crabs, which may influence their feeding behavior. Finally, since predator success is dependent on hydrodynamic conditions, prey behavior may also be dependent on hydrodynamic conditions. The 4 bulk mean crossflow velocity values chosen were within the velocity ranges experienced by clams in field conditions and were small enough to allow visual location of the clam jet in the PIV images.

After time records were recorded for the clams in this experiment, the nearest neighbor distances were altered and the clams were allowed to rebury themselves. The velocity measurements were repeated for varying bulk mean crossflow velocity treatments (again in a random order).

\section{Control data sets}

Three types of control data sets were collected in the laboratory flume for comparison with the above data sets. For each control case, PIV measurements were collected for each of the 4 bulk mean crossflow velocity values reported above. First, a control data set was collected above the clam plot without clams present to quantify the effects of the bumps and pockets in the sediment that were created during the clam burying process. Second, PIV images were captured above an empty clam shell to simulate the effects of a non-pumping clam. Third, 2 data sets were collected for a man-made vertical jet (diameter of $0.95 \mathrm{~cm}$ ) with 2 jet exit flow rates, 0.467 $\mathrm{cm}^{3} \mathrm{~s}^{-1}$ and $0.0 \mathrm{~cm}^{3} \mathrm{~s}^{-1}$. The mimic clam siphon (plastic tubing) extended $0.75 \mathrm{~cm}$ into the water column, which was a similar height to many of the clam siphons in the current study. For the case with a non-0 flow, the flow rate was specified such that the jet Reynolds number value for the jet mimic flow was within the range of those collected for the clam jets. The clam mimic case without jet flow gave the influence of the physical presence of the jet siphon.

\section{Velocity time record extraction}

The sequence of velocity vectors for 1 interrogation bin was extracted to create a velocity time record for a point in the flow field. A point was chosen to correspond to the excurrent jet region of the flow in order to extract a velocity time record for the clam siphon

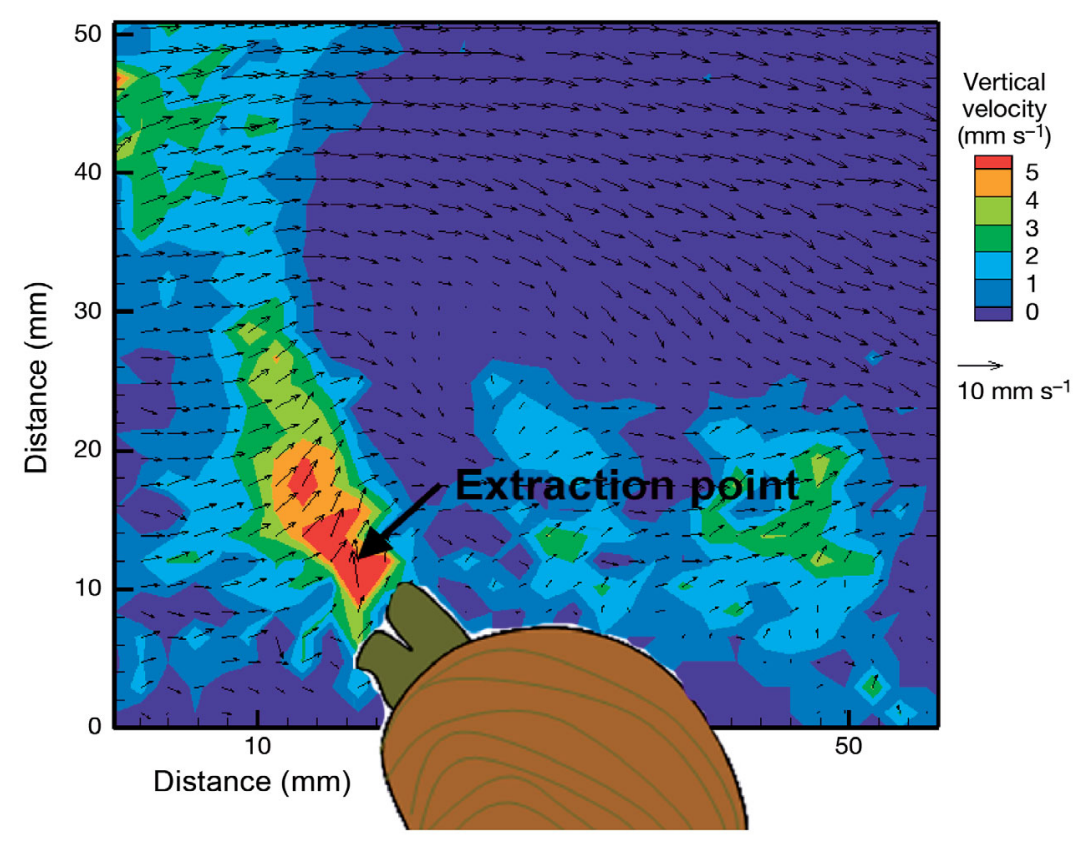

Fig. 2. Mercenaria mercenaria. Example instantaneous velocity vector field for a roughly $5 \mathrm{~cm}$ square plane bisecting a clam excurrent jet for the case with $U=0.55 \mathrm{~cm} \mathrm{~s}^{-1}$, clam length $=4.9 \mathrm{~cm}$, and a nearest neighbor distance of $9 \mathrm{~cm}$ (clam no. 5 listed in Table 1). The vertical excurrent jet is revealed by the red contours on the left side of the image. $U=$ bulk mean crossflow velocity 
vertical velocity (see example in Fig. 2). The point chosen varied according to the siphon location, siphon height, ambient velocity, and the presence of sufficient numbers of seeding particles, hence the extraction process required considerable manual observation of the images. Clams move their siphons while feeding by changing the height, width, and direction; they even close their siphons and open them again on a frequent basis (Tammes \& Dral 1956). Also, for larger ambient flow velocities, visually locating the siphon jet within the flow field became increasingly difficult. Therefore, the location of the extraction point depended on the individual organism and time record. There was little evidence that a systematic (i.e. programmable) method of determining an extraction point in the flow would give consistent results for this highly variable biological system.

The vertical velocity component of the jet velocity time record was chosen to represent the clam excurrent jet velocities. Employing the vertical component of the velocity provided a consistent representation of the fluctuations in the total excurrent signal, helped remove errors associated with the changes in excurrent siphon angle, and minimized the direct influence of the horizontal bulk flow in the measurements.

During resting periods, when the clam closed the excurrent siphon, the velocity time record did not provide velocities associated with the excurrent. The measured vertical velocity during the resting periods was due to the ambient flow, and these segments were removed from the time record analysis. Further, recorded values were removed from the velocity time record when the researcher could not identify the location of the excurrent jet. This occurred more often during larger ambient flow treatments. In other instances, the presence of feces or pseudo-feces interfered with the seeding particle recognition by the PIV code. With all of these situations and behaviors removed from the time record, the remaining data were a reliable capture of clam excurrent velocity behavior.

\section{Time record analyses}

\section{Spectral analysis}

Spectral analysis was employed to evaluate whether the time records of excurrent velocity possessed periodicity. Plotting the spectrum versus frequency revealed the relative amount of the time record variance that could have been explained by a periodicity at a particular frequency. The spectral analysis did not reveal any dominant frequencies and will not be discussed further, other than to conclude that the time records of clam excurrent vertical velocity lacked a dominant periodic variation.

\section{Fractal analysis}

Fractal analysis was used to quantify the random nature of the time record of excurrent velocity as first proposed by Hurst et al. (1947), quantified by Mandelbrot \& Van Ness (1968), and simplified by Fan et al. (1990). In the case of time record analysis, a fractal analysis yields a fractal dimension for the record between 1 and 2, with increasing values corresponding to a more space-filling record. As the value of the fractal dimension approaches 1.5 from above or below, the time record becomes more random as it more closely resembles fractional Brownian motion. In cases where the calculated fractal dimension value is between 1 and 1.5, the time record can be considered correlated. In other words, one value of velocity is followed closely by a similar value of velocity. As the fractal dimension increases from 1 and approaches a value of 1.5 , the velocity time record values become less correlated and more random. On the other hand, when fractal dimension values are between 1.5 and 2 , the velocity time record is considered anti-correlated. In an anti-correlated time record, one value of velocity is followed by a dissimilar value of velocity. The most highly anti-correlated time records have fractal dimension values close to 2 with more random velocity values as the fractal dimension approaches 1.5.

Here, the fractal dimension of the time series was calculated to evaluate whether the nature of the flow unsteadiness varied under varying environmental conditions. Estimates of the fractal dimension were averaged over the ensemble of time records to yield an ensemble averaged value of fractal dimension, $d_{\mathrm{fl}}$, for each treatment case. Hurst's rescaled range analysis was employed, yielding values of the Hurst exponent, $H$. The $H$ exponent is related to the fractal dimension:

$$
d_{\mathrm{fl}}=2-H
$$

Random walk or fractional Brownian motion has time record values with 'jumps' or 'step sizes' with magnitudes corresponding to Gaussian white noise, and the Hurst's rescaled range analysis is a measure of the randomness of the differences in the values of the time record. Let $B(t)$ be a time record of equallyspaced data (in this case, a clam jet velocity time record). The time record of step sizes $X(t)$ is defined 
by $X(0)=0$ and $X(t)=[B(t)-B(t-d t)]$, where $d t$ is the time step between image pairs. $C(t, u)$ is the cumulative departure of $X(t+y)$ from the mean, $\langle X(t)\rangle_{S}$, for the sub-record:

$$
c(t, u)=\sum_{y=1}^{u}\left[X(t+y)-\langle X(t)\rangle_{s}\right]
$$

where $s$ is the time lag, $u=1,2, \ldots, s$, and $y$ is a time value from 1 to $u$. The sample range of $X(t)$ for lag $s$ is:

$$
R(t, s)=\max _{0<u \leq S} C(t, u)-\min _{0<u \leq S} c(t, u)
$$

and the sample variance of $X(t)$ is:

$$
S^{2}(t, s)=\frac{1}{s} \sum_{u=1}^{s}\left\{X(t+u)-\langle X(t)\rangle_{s}\right\}^{2}
$$

giving the scaling relationship (Fan et al. 1990):

$$
\frac{R(t, s)}{S(t, s)} \propto S^{H}
$$
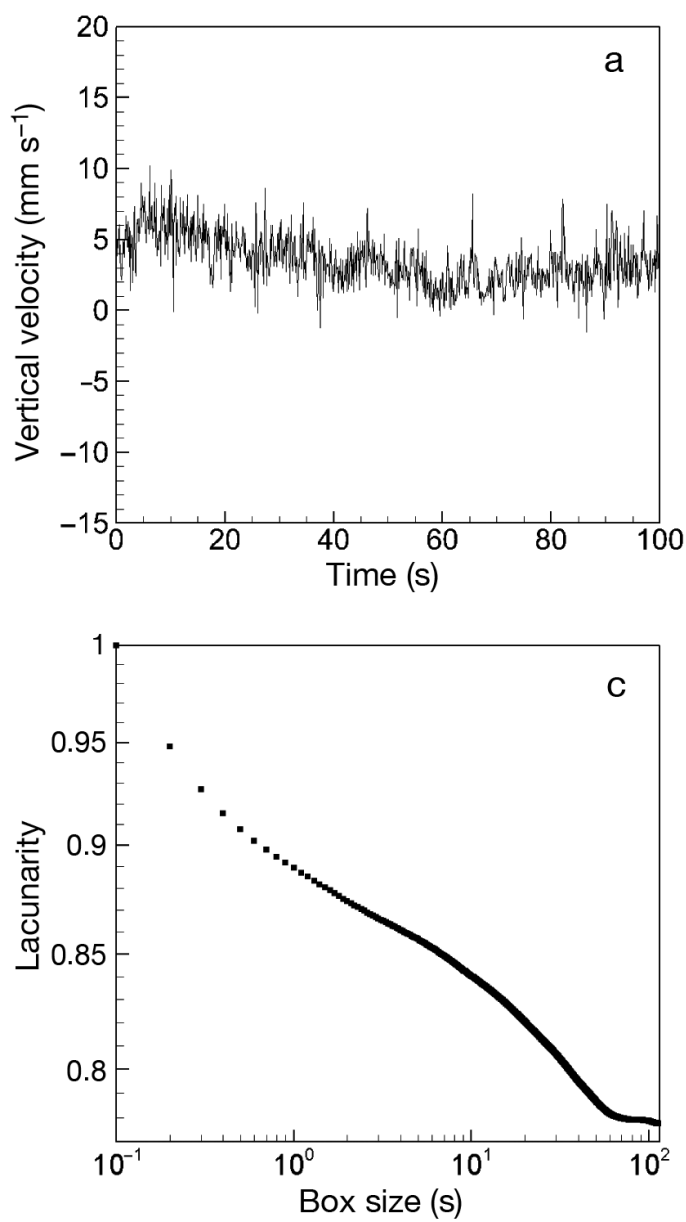

In practice, $H$ was calculated via Eq. (5) using the slope of a least squares regression of a plot of $\frac{R(t, s)}{S(t, s)}$ versus the time lag, $s$ (on log-log axes). The fractal dimension of the time series was then determined using Eq. (1).

\section{Lacunarity analysis}

Lacunarity analysis was employed to quantify the 'look' of the distribution or quantify the size and location of the 'space' between values of the velocity. While the fractal dimension was considered a measure of how much space was filled or the amount of 'mass' within a geometric space, lacunarity was a measure of how the space was filled with that mass. In the current work, lacunarity analysis was employed because some time records had similar fractal dimensions, while they were quite distinct visually.
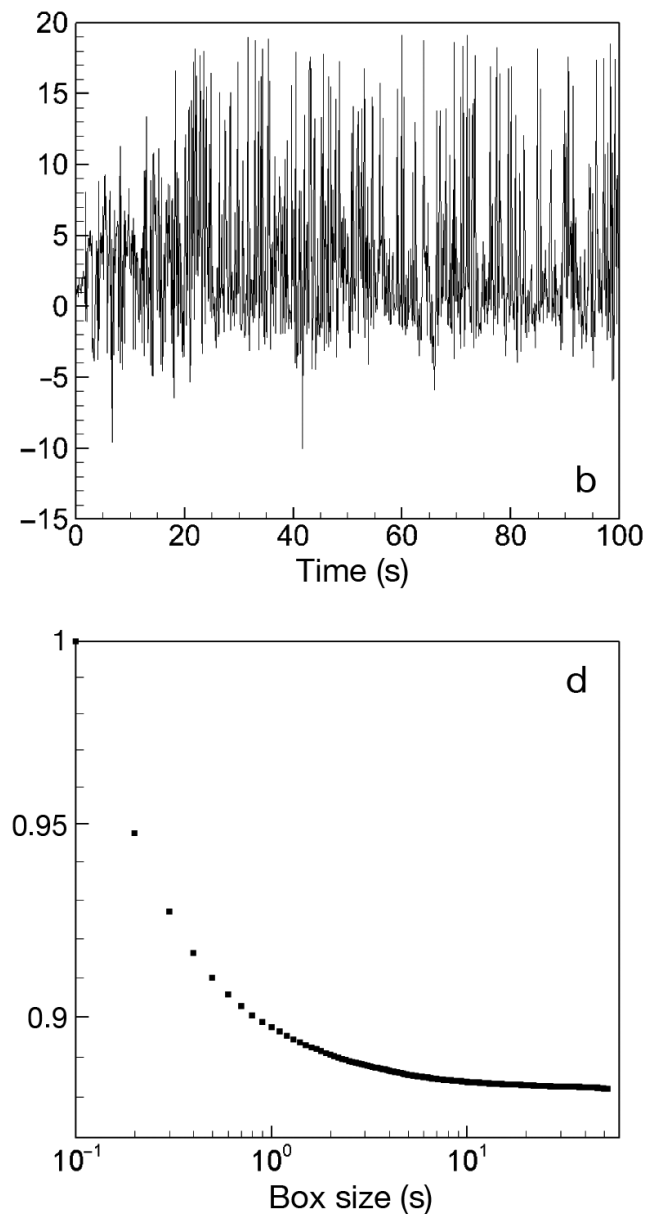

Fig. 3. Mercenaria mercenaria. Example velocity time records and lacunarity curves. (a) Time record of vertical velocity in the excurrent jet, and (c) corresponding lacunarity curve, for clam with $U=0.55 \mathrm{~cm} \mathrm{~s}^{-1}$, clam length $=4.9 \mathrm{~cm}$, and a nearest neighbor distance (NND) of $9 \mathrm{~cm}$ (clam no. 5 listed in Table 1); fractal dimension $=1.77$. (b) Time record, and (d) corresponding lacunarity curve, for the same clam and NND but with $U=1.2 \mathrm{~cm} \mathrm{~s}^{-1}$; fractal dimension $=1.78$ 
Lacunarity is a means of quantifying the 'texture' of distributions that appear very different, yet have the same fractal dimension (Allain \& Cloitre 1991). As an example, Fig. 3a,b shows 2 time records with similar fractal dimension values that possess different 'textures.'

Lacunarity analysis was applied by Allain \& Cloitre (1991) to describe the heterogeneity of binary datasets, and Plotnick et al. (1996) extended the analysis to quantitative data. The lacunarity analysis chooses a unit box of size $r$ and sums the values in the box, $v$ (i.e. the sum of the velocity values in our case). First, the record was shifted such that there were no negative values in the time record, the gliding box was centered on each point in the data set, and the (velocity) values within the box were summed. The gliding box lacunarity is defined as (Tolle et al. 2008):

$$
\Lambda_{\mathrm{GB}}(r)=\frac{Z^{(2)}(r)}{\left(Z^{(1)}(r)\right)^{2}}
$$

where:

$$
\begin{aligned}
& Z^{(1)}(r)=\frac{1}{N-r+1} \sum_{i=1}^{N-r+1}\left[\sum_{j=1}^{i+r-1} v_{j}\right] \\
& Z^{(2)}(r)=\frac{1}{N-r+1} \sum_{i=1}^{N-r+1}\left[\sum_{j=1}^{i+r-1} v_{j}\right]^{2}
\end{aligned}
$$

and $N$ was the sample size of the velocity time record.

Lacunarity was calculated and plotted as a function of the size of the box, $r$, in units of seconds (see Fig. 3c,d). The lacunarity curves shown here were normalized by the lacunarity value at the smallest box size for comparison purposes. The shape of the lacunarity curve revealed the deviation of an object (in this case the time record) from established geometric patterns (Plotnick et al. 1996). Further, the shape of the lacunarity curve indicated features of the velocity time record. For example, high lacunarity values indicated clumping or closely clustered values of velocity. At a box size value that corresponded to the size of the clumped or clustered values, the lacunarity value decreased and the curve dropped off as can be seen in the example in Fig. 4b. There is a distinct break in the slope of the lacunarity curve at a box size of $\sim 3 \mathrm{~s}$. Another example is shown in Fig. 3c. Also, time records that have gap sizes with random step size values have a lacunarity curve with a concave-upward shape. For example, Fig. 4c for a large clam with large nearest neighbor distance and the largest bulk mean crossflow velocity matches this description (see also Fig. 3d). Finally, fractals, by definition, have a power law relationship between geometric ratios and the box size, which means that on a log-log scale, a lacunarity curve is a straight line for a pure fractal. An example is shown in Fig. 4a.

We categorized the shape of the lacunarity curves for the time records of vertical velocity in the clam excurrent. The lacunarity curves were assigned a nominal category upon visual inspection of the curve of either 'Random' for a shape similar to that of Fig. 4c, 'Fractal' for a shape similar to that of Fig. 4a, and 'Size' for a curve with a distinct break in slope similar to that of Fig. $4 \mathrm{~b}$.
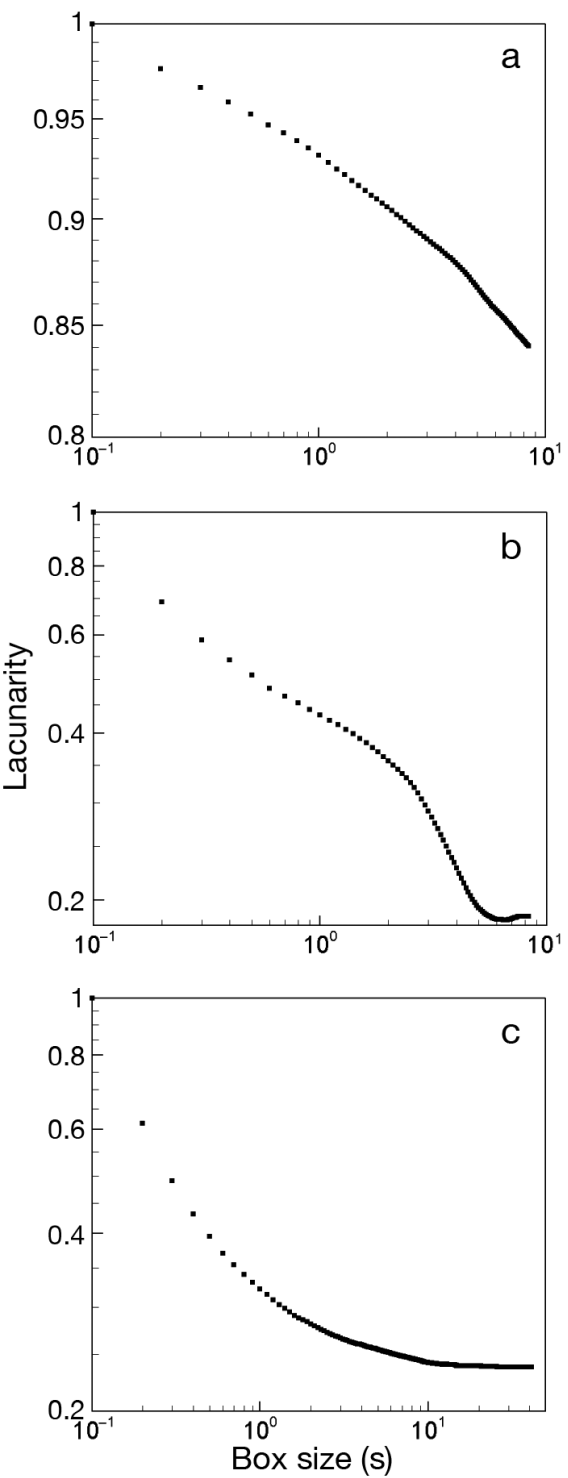

Fig. 4. Mercenaria mercenaria. Lacunarity as a function of box size (i.e. time segment) for the time record of vertical jet velocity (on log axes). (a) Clam no. 4 of Table 1 for $U=$ $2.86 \mathrm{~cm} \mathrm{~s}^{-1}$, clam length $=4.6 \mathrm{~cm}$, and nearest neighbor distance of $3 \mathrm{~cm}$; (b) Clam no. 6 of Table 1 for $U=2.86 \mathrm{~cm} \mathrm{~s}^{-1}$, clam length $=7.30 \mathrm{~cm}$, and nearest neighbor distance of $3 \mathrm{~cm}$; and (c) Clam no. 8 of Table 1 for $U=2.86 \mathrm{~cm} \mathrm{~s}^{-1}$, clam length $=6.91 \mathrm{~cm}$, and nearest neighbor distance of $9 \mathrm{~cm}$ 
Often there were several time records for each treatment case due to the removal of periods in which the clam stopped pumping, the siphon changed location, or the researcher could not locate the excurrent jet in the velocity field. In the cases where multiple velocity records existed for a treatment, the lacunarity curves were plotted for each of the time record segments. In most of the cases with multiple velocity records, the shapes of the lacunarity plots were similar. In the few cases where there were differences in the lacunarity plot shapes for the multiple velocity records, the dominant lacunarity shape type was recorded for that case.

\section{Statistical tests}

To characterize the clam jet velocity time records, several multi-way, repeated measures analysis of variance (ANOVA) and nominal ANOVA (NANOVA) tests were performed for the mean excurrent jet vertical velocity values, the jet-to-crossflow velocity ratios, the fractal dimensions, and the lacunarity plot shape designations. The repeated measures aspect of the ANOVA was the fact that individual clams were subjected to several treatment scenarios and could not be treated as unrelated replicates.

NANOVA is an extension of the ANOVA to data sets that are nominal rather than quantitative (Weiss 2009) and was used in this study to qualitatively differentiate the nominal shape designations of the lacunarity analysis performed on the clam excurrent jet velocity time records. Without quantitative values from the lacunarity analysis, the test could only determine whether the nominal values were qualitatively different, but not necessarily how they differed quantitatively. NANOVAs were used to determine whether the lacunarity plot shape designations were statistically different for each treatment case. The NANOVA in the current study revealed whether the randomness (for excurrent velocity values) was different in the treatments and lacked the ability to conclude whether an experimental treatment resulted in more or less randomness (for excurrent velocity values) than another treatment.

\section{RESULTS}

\section{Example case}

An example of a velocity field is shown in Fig. 2 where the arrows represent the local velocity vector and the color contours represent positive (upward) vertical velocity. This example set will be used throughout this section for demonstration purposes, and it is typical of the results for the entire data set. The color contours highlight the location of the clam excurrent jet. The location of the buried clam is shown for clarity. In this particular example, the clam was not completely buried beneath the sediment, and the siphons were extended in the upstream direction with the incurrent siphon located upstream of the excurrent siphon. While this example should be considered typical, the specific characteristics may or may not occur in other cases of this study.

Approximately 2250 consecutive velocity fields were collected for this case. The vertical velocity time record of $225 \mathrm{~s}$ duration was extracted, and the first $100 \mathrm{~s}$ are displayed in Fig. 3a. The time record of clam excurrent vertical velocity is highly unsteady with a mean of $v=3.26 \mathrm{~mm} \mathrm{~s}^{-1}$ and variance of $\sigma^{2}=$ $3.07 \mathrm{~mm}^{2} \mathrm{~s}^{-2}$. A few negative values of vertical velocity appear in the time record, which can be attributed to brief intrusions of the ambient fluid to the centerline of the jet.

For this example time record (Fig. 3a), the fractal dimension is 1.77, which, being greater than 1.5, indicates that the record is anti-correlated. Fig. 3c shows lacunarity as a function of box size for the time record shown in Fig. 3a. Alternatively, Fig. 3b shows the velocity time record for the same clam with a different bulk mean crossflow velocity regime. The time records have similar fractal dimension values, but appear to have differing distributions (or texture) of the velocity values. This differing 'look' is quantified in the lacunarity curves in Fig. 3c,d. The lacunarity plot type for the jet velocity time record for a bulk mean crossflow velocity of $0.55 \mathrm{~cm} \mathrm{~s}^{-1}$ is 'Size' (Fig. 3c) and for bulk mean crossflow velocity of $1.2 \mathrm{~cm} \mathrm{~s}^{-1}$ is 'Random' (Fig. 3d).

\section{Clam jets with varying environmental conditions}

Table 1 (mean and SD of the excurrent jet vertical velocity), Table 2 (jet-to-crossflow velocity ratio, Table 3 (fractal dimension), and Table 4 (lacunarity curve type) summarize the time record collection for the controlled external factors: 4 horizontal bulk mean crossflow velocity values $(0.55,1.2,1.98$, $2.86 \mathrm{~cm} \mathrm{~s}^{-1}$ ), 2 nearest neighbor distances (3 and $9 \mathrm{~cm})$, and 2 clam sizes $(4.86 \pm 0.22 \mathrm{~cm}$ and $7.32 \pm$ $0.32 \mathrm{~cm}$ ). Non-dimensionalizing the nearest neighbor distance by the mean clam size in each case yielded 
Table 2. Mercenaria mercenaria. Jet-to-crossflow velocity ratio, $V / U$. The table reports data for varying nearest neighbor distance (NND), non-dimensional NND ( $\left.{ }^{\text {nd }} \mathrm{NND}\right)$, bulk mean crossflow velocity $\left(U, \mathrm{~cm} \mathrm{~s}^{-1}\right)$, and clam size class. $v=$ jet vertical velocity

\begin{tabular}{|c|c|c|c|c|}
\hline \multirow[t]{2}{*}{ Clam } & \multirow{2}{*}{$\begin{array}{l}\text { Length } \\
\text { (cm) }\end{array}$} & \multirow{2}{*}{$\begin{array}{c}U \\
\left(\mathrm{~cm} \mathrm{~s}^{-1}\right)\end{array}$} & \multicolumn{2}{|c|}{$V / U$} \\
\hline & & & $\begin{array}{c}\mathrm{NND}=3 \mathrm{~cm} \\
{ }^{\mathrm{nd}} \mathrm{NND}=0.62\end{array}$ & $\begin{array}{c}\mathrm{NND}=9 \mathrm{~cm} \\
{ }^{\mathrm{nd} N N D}=1.85\end{array}$ \\
\hline \multirow[t]{4}{*}{1} & \multirow[t]{4}{*}{4.7} & 0.55 & 0.58 & 0.57 \\
\hline & & 1.20 & 0.38 & 0.30 \\
\hline & & 1.98 & 0.29 & 0.41 \\
\hline & & 2.86 & 0.08 & 0.10 \\
\hline \multirow[t]{4}{*}{2} & \multirow[t]{4}{*}{5.2} & 0.55 & 0.76 & 1.9 \\
\hline & & 1.20 & 0.07 & 0.37 \\
\hline & & 1.98 & 0.04 & 0.23 \\
\hline & & 2.86 & 0.06 & 0.12 \\
\hline \multirow[t]{4}{*}{3} & \multirow[t]{4}{*}{4.9} & 0.55 & 0.36 & 0.95 \\
\hline & & 1.20 & 0.37 & 0.14 \\
\hline & & 1.98 & 0.09 & 0.03 \\
\hline & & 2.86 & 0.06 & 0.05 \\
\hline \multirow[t]{4}{*}{4} & \multirow[t]{4}{*}{4.6} & 0.55 & 0.89 & 0.63 \\
\hline & & 1.20 & 0.58 & 0.67 \\
\hline & & 1.98 & 0.13 & 0.21 \\
\hline & & 2.86 & 0.09 & 0.01 \\
\hline \multirow[t]{4}{*}{5} & \multirow[t]{4}{*}{4.9} & 0.55 & 1.39 & 0.59 \\
\hline & & 1.20 & 0.20 & 0.26 \\
\hline & & 1.98 & 0.10 & 0.15 \\
\hline & & 2.86 & 0.02 & 0.09 \\
\hline \multirow[t]{2}{*}{ Clam } & \multirow{2}{*}{$\begin{array}{l}\text { Length } \\
(\mathrm{cm})\end{array}$} & \multirow{2}{*}{$\begin{array}{c}U \\
\left(\mathrm{~cm} \mathrm{~s}^{-1}\right)\end{array}$} & \multicolumn{2}{|c|}{$v / U$} \\
\hline & & & $\begin{array}{c}\overline{\mathrm{NND}}=3 \mathrm{~cm} \\
{ }^{\mathrm{nd}} \mathrm{NND}=0.41\end{array}$ & $\begin{array}{c}\overline{\mathrm{NND}}=9 \mathrm{~cm} \\
{ }^{\mathrm{nd} N N D}=1.23\end{array}$ \\
\hline \multirow[t]{4}{*}{6} & \multirow[t]{4}{*}{7.3} & 0.55 & 0.42 & 0.29 \\
\hline & & 1.20 & 0.07 & 0.14 \\
\hline & & 1.98 & 0.07 & 0.11 \\
\hline & & 2.86 & 0.03 & 0.16 \\
\hline \multirow[t]{4}{*}{7} & \multirow[t]{4}{*}{7.5} & 0.55 & 0.7 & 0.48 \\
\hline & & 1.20 & 0.28 & 0.20 \\
\hline & & 1.98 & 0.21 & 0.05 \\
\hline & & 2.86 & 0.11 & 0.07 \\
\hline \multirow[t]{4}{*}{8} & \multirow[t]{4}{*}{6.9} & 0.55 & 0.59 & 0.33 \\
\hline & & 1.20 & 0.41 & 0.22 \\
\hline & & 1.98 & 0.29 & 0.10 \\
\hline & & 2.86 & 0.22 & 0.19 \\
\hline \multirow[t]{4}{*}{9} & \multirow[t]{4}{*}{8.6} & 0.55 & 0.35 & 0.95 \\
\hline & & 1.20 & 0.17 & 0.27 \\
\hline & & 1.98 & 0.16 & 0.08 \\
\hline & & 2.86 & 0.18 & 0.04 \\
\hline
\end{tabular}

non-dimensional nearest neighbor distances of 0.62 and 1.85 for the smaller size clams and 0.41 and 1.23 for the larger size clams, respectively, for the 3 and $9 \mathrm{~cm}$ spacing distances.

Mean vertical jet velocities were determined for each of the treatment combinations given in Table 1, and an average of all mean vertical jet velocities over all treatments results in $v=3.24 \pm 2.01 \mathrm{~mm} \mathrm{~s}^{-1}$.
A multi-way, repeated measures ANOVA on the vertical jet velocities revealed a significant interaction $(p<0.034)$ for the mean jet velocities according to the length of the clam and the bulk mean crossflow velocity. In other words, the clam's mean jet velocity values were influenced by the bulk mean crossflow velocity, and those values were dependent on the size of the clam. Due to the interaction, we were unable to compare the individual means of the 2 factors. Table 1 reveals no distinct patterns in the mean clam jet velocity values, and further analysis of the velocity patterns were required to determine clam behavioral differences in the treatments. The jet-tocrossflow velocity ratio and the lacunarity analysis were able to reveal distinct patterns in the clam behavior despite a lack of pattern in the mean values, spectral analysis, and fractal analysis.

By non-dimensionalizing the clam jet mean vertical velocity values by the crossflow velocity, the jet-
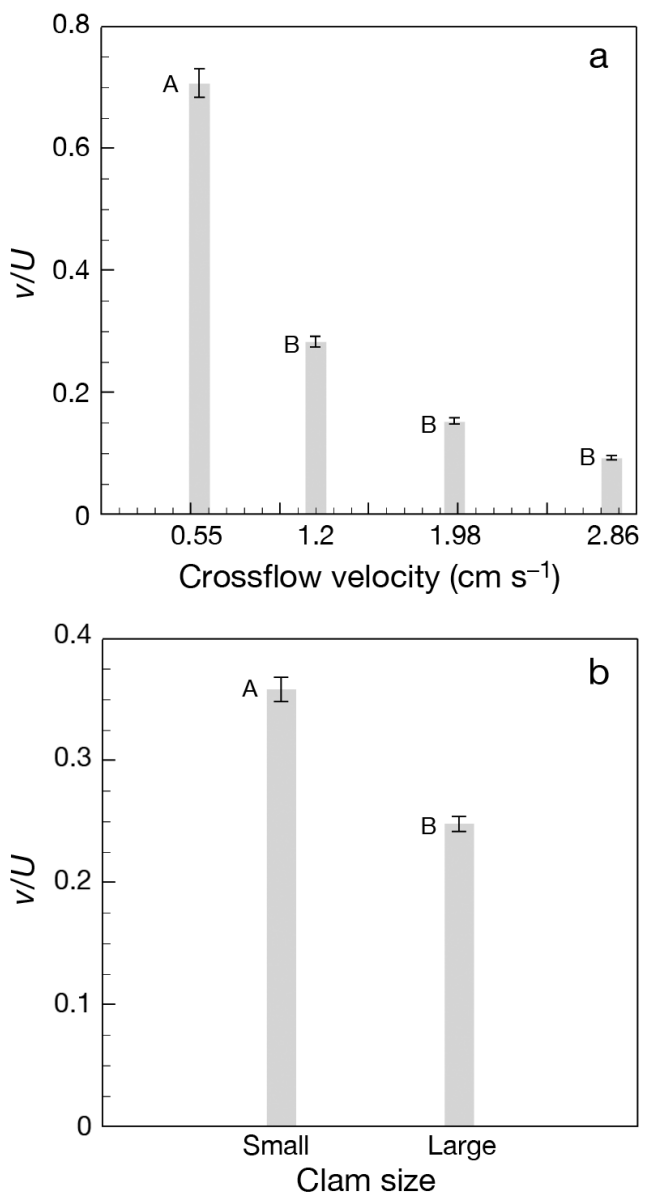

Fig. 5. Mercenaria mercenaria. Mean jet-to-crossflow velocity ratio, $v / U,(a)$ according to bulk mean crossflow velocity value ( $\mathrm{p}<0.001)$, and (b) according to clam size class ( $\mathrm{p}<$ 0.044). Error bars represent SE. Different letters indicate significant difference 
to-crossflow velocity ratios could be compared for each treatment case (Table 2). If the clams were maintaining the velocity values, as the results of Price \& Schiebe (1978) suggest, then the mean jetto-crossflow velocity ratio should have decreased linearly with increasing bulk mean crossflow velocity. A multi-way, repeated measures ANOVA on the clam jet-to-crossflow velocity ratios did not find an interaction between the factors (size of clam, nearest neighbor distance, or bulk mean crossflow velocity ratio) which allowed us to compare the means of the factors separately. There was a significant difference in the mean jet-to-crossflow velocity ratios according to the size of the clam $(p<0.044)$ and according to the bulk mean crossflow velocity $(\mathrm{p}<0.001)$. The mean jet-to-crossflow velocity ratio at a bulk mean crossflow velocity of $0.55 \mathrm{~cm} \mathrm{~s}^{-1}$ was significantly different than the mean jet-to-crossflow velocity ratio of the 3 other bulk mean crossflow velocity values $(\mathrm{p}<0.05$; see Fig. 5a). As the jet-to-crossflow velocity ratio did not decrease in proportion to the inverse of the bulk mean crossflow velocity (i.e. the normalization), the results indicated that clams were altering their jet velocity value as the bulk mean crossflow velocity changed. Also, they were not maintaining a constant jet-to-crossflow velocity ratio, particularly for the smallest bulk mean crossflow velocity case. Finally, the mean jet-to-crossflow velocity ratio for the smaller size clams $(v / U=0.358 \pm 0.01 \mathrm{SE})$ was significantly larger than that for the larger size clams $(v / U=0.248$ \pm 0.006 SE; Fig. 5b).

The fractal dimension values captured here were generally anti-correlated (Table 3). In other words, a value of velocity in the time record was followed by a dissimilar value of velocity. A multi-way, repeated measures ANOVA found no significant differences or significant interactions in the mean fractal dimension values of the time records according to bulk mean crossflow velocity, clam nearest neighbor distance, or clam size (Table 3). There was a distinct lack of pattern in the fractal dimension values presented in Table 3; however, the values of the fractal dimension in Table 3 give a sense of the amount of randomness contained in the velocity time record. The lack of pattern in Table 3 justifies the use of the lacunarity analysis as a means of quantifying the texture of the velocity time record randomness.

The lacunarity curves were categorized with nominal types according to the shape (Table 4). A multiway, repeated measures NANOVA of the lacunarity nominal values in Table 4 found a significant difference in the lacunarity curves according to the hori-
Table 3. Mercenaria mercenaria. Fractal dimension $\left(d_{\mathrm{fl}}\right)$ for the time records of vertical velocity in the clam excurrent jet. The table reports data for varying nearest neighbor distance (NND), non-dimensional NND ( $\left.{ }^{\text {nd }} \mathrm{NND}\right)$, bulk mean crossflow velocity $\left(\mathrm{cm} \mathrm{s}^{-1}\right)$, and clam size class

\begin{tabular}{|c|c|c|c|c|}
\hline Clam & $\begin{array}{c}\text { Length } \\
\text { (cm) }\end{array}$ & $\begin{array}{c}U \\
\left(\mathrm{~cm} \mathrm{~s}^{-1}\right)\end{array}$ & $\begin{array}{l}d_{\mathrm{fl}} \\
\mathrm{NND}=3 \mathrm{~cm} \\
{ }^{\mathrm{nd} N N D}=0.62\end{array}$ & $\begin{array}{l}\overline{N N D=9 \mathrm{~cm}} \\
{ }^{\mathrm{nd} N N D=1.85}\end{array}$ \\
\hline 1 & 4.7 & $\begin{array}{l}0.55 \\
1.20 \\
1.98 \\
2.86\end{array}$ & $\begin{array}{l}1.80 \\
1.86 \\
1.83 \\
1.79\end{array}$ & $\begin{array}{l}1.74 \\
1.64 \\
1.73 \\
1.75\end{array}$ \\
\hline 2 & 5.2 & $\begin{array}{l}0.55 \\
1.20 \\
1.98 \\
2.86\end{array}$ & $\begin{array}{l}1.66 \\
1.76 \\
1.79 \\
1.70\end{array}$ & $\begin{array}{l}1.72 \\
1.76 \\
1.67 \\
1.74\end{array}$ \\
\hline 3 & 4.9 & $\begin{array}{l}0.55 \\
1.20 \\
1.98 \\
2.86\end{array}$ & $\begin{array}{l}1.74 \\
1.79 \\
1.72 \\
1.71\end{array}$ & $\begin{array}{l}1.69 \\
1.67 \\
1.81 \\
1.69\end{array}$ \\
\hline 4 & 4.6 & $\begin{array}{l}0.55 \\
1.20 \\
1.98 \\
2.86\end{array}$ & $\begin{array}{l}1.75 \\
1.73 \\
1.70 \\
1.67\end{array}$ & $\begin{array}{l}1.82 \\
1.81 \\
1.72 \\
1.57\end{array}$ \\
\hline 5 & 4.9 & $\begin{array}{l}0.55 \\
1.20 \\
1.98 \\
2.86\end{array}$ & $\begin{array}{l}1.61 \\
1.78 \\
1.70 \\
1.80\end{array}$ & $\begin{array}{l}1.77 \\
1.78 \\
1.80 \\
1.66\end{array}$ \\
\hline Clam & $\begin{array}{l}\text { Length } \\
(\mathrm{cm})\end{array}$ & $\begin{array}{c}U \\
\left(\mathrm{~cm} \mathrm{~s}^{-1}\right)\end{array}$ & $\begin{array}{l}\overline{\mathrm{NND}}=3 \mathrm{~cm} \\
{ }_{\mathrm{fl}} \\
{ }^{\mathrm{nd} N D}=0.41\end{array}$ & $\begin{array}{l}\overline{\mathrm{NND}=9 \mathrm{~cm}} \\
{ }^{\mathrm{nd} N N D=1.23}\end{array}$ \\
\hline 6 & 7.3 & $\begin{array}{l}0.55 \\
1.20 \\
1.98 \\
2.86\end{array}$ & $\begin{array}{l}1.75 \\
1.76 \\
1.73 \\
1.67\end{array}$ & $\begin{array}{l}1.82 \\
1.81 \\
1.76 \\
1.86\end{array}$ \\
\hline 7 & 7.5 & $\begin{array}{l}0.55 \\
1.20 \\
1.98 \\
2.86\end{array}$ & $\begin{array}{l}1.76 \\
1.78 \\
1.78 \\
1.80\end{array}$ & $\begin{array}{l}1.74 \\
1.81 \\
1.84 \\
1.74\end{array}$ \\
\hline 8 & 6.9 & $\begin{array}{l}0.55 \\
1.20 \\
1.98 \\
2.86\end{array}$ & $\begin{array}{l}1.72 \\
1.75 \\
1.58 \\
1.73\end{array}$ & $\begin{array}{l}1.83 \\
1.79 \\
1.51 \\
1.84\end{array}$ \\
\hline 9 & 8.6 & $\begin{array}{l}0.55 \\
1.20 \\
1.98 \\
2.86\end{array}$ & $\begin{array}{l}1.80 \\
1.77 \\
1.63 \\
1.79\end{array}$ & $\begin{array}{l}1.70 \\
1.79 \\
1.73 \\
1.68\end{array}$ \\
\hline
\end{tabular}

zontal bulk mean crossflow velocity $(p<0.001)$. The NANOVA revealed that the clams were changing the jet velocities in such a way that the lacunarity curve shape changed with the bulk mean crossflow velocity value. Therefore, although the amount of randomness in the velocity time records may be statistically similar (as measured by fractal dimension), the distribution of the randomness or the texture of the randomness was bulk mean crossflow velocity 
Table 4. Mercenaria mercenaria. Lacunarity curve type for time records of clam excurrent vertical velocity (see 'Materials and methods' for a description of the curve types). The table reports data for varying nearest neighbor distance (NND), non-dimensional NND ( $\left.{ }^{\text {nd }} \mathrm{NND}\right)$, bulk mean crossflow velocity $\left(U, \mathrm{~cm} \mathrm{~s}^{-1}\right)$, and clam size class

\begin{tabular}{|c|c|c|c|c|}
\hline \multirow[t]{2}{*}{ Clam } & \multirow{2}{*}{$\begin{array}{l}\text { Length } \\
(\mathrm{cm})\end{array}$} & \multirow{2}{*}{$\begin{array}{c}U \\
\left(\mathrm{~cm} \mathrm{~s}^{-1}\right)\end{array}$} & \multicolumn{2}{|c|}{ — Lacunarity curve type _- } \\
\hline & & & $\begin{array}{c}\mathrm{NND}=3 \mathrm{~cm} \\
{ }^{\mathrm{nd}} \mathrm{NND}=0.62\end{array}$ & $\begin{array}{c}\mathrm{NND}=9 \mathrm{~cm} \\
\text { nd NND }=1.85\end{array}$ \\
\hline \multirow[t]{4}{*}{1} & \multirow[t]{4}{*}{4.7} & 0.55 & Random & Size \\
\hline & & 1.20 & Random & Size \\
\hline & & 1.98 & Random & Random \\
\hline & & 2.86 & Random & Random \\
\hline \multirow[t]{4}{*}{2} & \multirow[t]{4}{*}{5.2} & 0.55 & Size & Random \\
\hline & & 1.20 & Size & Random \\
\hline & & 1.98 & Random & Size \\
\hline & & 2.86 & Random & Size \\
\hline \multirow[t]{4}{*}{3} & \multirow[t]{4}{*}{4.9} & 0.55 & Random & Size \\
\hline & & 1.20 & Size & Size \\
\hline & & 1.98 & Size & Random \\
\hline & & 2.86 & Fractal & Size \\
\hline \multirow[t]{4}{*}{4} & \multirow[t]{4}{*}{4.6} & 0.55 & Size & Random \\
\hline & & 1.20 & Size & Random \\
\hline & & 1.98 & Random & Size \\
\hline & & 2.86 & Fractal & Size \\
\hline \multirow[t]{4}{*}{5} & \multirow[t]{4}{*}{4.9} & 0.55 & Size & Size \\
\hline & & 1.20 & Size & Random \\
\hline & & 1.98 & Size & Random \\
\hline & & 2.86 & Random & Fractal \\
\hline \multirow[t]{2}{*}{ Clam } & \multirow{2}{*}{$\begin{array}{l}\text { Length } \\
(\mathrm{cm})\end{array}$} & \multirow{2}{*}{$\begin{array}{c}U \\
\left(\mathrm{~cm} \mathrm{~s}^{-1}\right)\end{array}$} & \multicolumn{2}{|c|}{ _ Lacunarity curve type __ } \\
\hline & & & $\begin{array}{c}\text { NND }=3 \mathrm{~cm} \\
\text { nd NND }=0.41\end{array}$ & $\begin{array}{c}\mathrm{NND}=9 \mathrm{~cm} \\
\text { nd NND }=1.23\end{array}$ \\
\hline \multirow[t]{4}{*}{6} & \multirow[t]{4}{*}{7.3} & 0.55 & Random & Random \\
\hline & & 1.20 & Size & Size \\
\hline & & 1.98 & Size & Fractal \\
\hline & & 2.86 & Size & Random \\
\hline \multirow[t]{4}{*}{7} & \multirow[t]{4}{*}{7.5} & 0.55 & Size & Random \\
\hline & & 1.20 & Random & Random \\
\hline & & 1.98 & Random & Random \\
\hline & & 2.86 & Random & Random \\
\hline \multirow[t]{4}{*}{8} & \multirow[t]{4}{*}{6.9} & 0.55 & Fractal & Random \\
\hline & & 1.20 & Random & Random \\
\hline & & 1.98 & Fractal & Random \\
\hline & & 2.86 & Random & Random \\
\hline \multirow[t]{4}{*}{9} & \multirow[t]{4}{*}{8.6} & 0.55 & Random & Fractal \\
\hline & & 1.20 & Size & Random \\
\hline & & 1.98 & Size & Random \\
\hline & & 2.86 & Random & Random \\
\hline
\end{tabular}

specific. A limitation of the NANOVA test is that when a significant difference is found in the nominal values, there is no way to quantify that difference. The texture of the velocity time records were different, but we cannot report a measure of how they were different.

The NANOVA test on the nominal values in Table 4 also revealed a significant interaction between the nearest neighbor distance and clam size $(\mathrm{p}<0.001)$. The lacunarity plot shape was dependent on the size of the organism, and that dependence was influenced by the proximity of other clams. The most significant trend was that there are a large number of 'Random' plot shapes for the larger clams (Table 4). Further, there appeared to be more 'Random' plot shapes for the $9 \mathrm{~cm}$ nearest neighbor distances (Table 4). The interaction between the nearest neighbor distance and the size of the organism implied that the reaction of clams to the density of the clam patch was dependent on the size of that particular animal. Hence, there may be specific clam patch densities that are advantageous for organisms of a specific size.

\section{Control cases}

Table 5 summarizes the data for the control treatments. Two-way, repeated-measures ANOVA tests revealed that there was no interaction between factors for mean velocities and jet-to-crossflow velocity ratios, which allowed a comparison of means. There was a significant difference in the mean vertical velocities $(p<0.001)$ and in the mean jet-to-crossflow velocity ratios $(p<0.03)$ according to the control type (e.g. clam shell only, clam mimic). The clam mimic case with jet flow rate of $=0.467 \mathrm{~cm}^{3} \mathrm{~s}^{-1}$ had significantly larger values of the mean vertical velocity and the mean jet-to-crossflow velocity ratio.

A 2-way, repeated measures ANOVA did not find interactions between factors or significant differences in the mean fractal dimension values among the control cases for any of the factors (bulk mean crossflow velocity and control type). The lacunarity curve types for the control cases are presented in Table 5, and the majority of cases are described as 'Random.' A 2-way, repeated measures NANOVA found no interaction between factors and significant difference in lacunarity curve type for the control cases according to bulk mean crossflow velocity ( $p<$ $0.001)$.

\section{DISCUSSION}

\section{Clam pumping behavior}

Clams altered their excurrent flow behavior according to bulk mean crossflow velocity as seen in the lacunarity analysis and the jet-to-crossflow velocity ratios (Tables $2 \& 4$ and Fig. 5). Also, the reaction 
Table 5. Data for time records of vertical velocity for the laboratory control cases. $U=$ bulk mean crossflow velocity, $v=$ jet vertical velocity $($ mean $\pm \mathrm{SD}), d_{\mathrm{fl}}=$ fractal dimension

\begin{tabular}{|c|c|c|c|c|c|c|c|}
\hline & $\begin{array}{l}\text { Jet flow rate } \\
\qquad\left(\mathrm{cm}^{3} \mathrm{~s}^{-1}\right)\end{array}$ & $\begin{array}{l}\text { Diameter } \\
\quad(\mathrm{cm})\end{array}$ & $\begin{array}{c}U \\
\left(\mathrm{~cm} \mathrm{~s}^{-1}\right)\end{array}$ & $\begin{array}{c}V \\
\left(\mathrm{~mm} \mathrm{~s}^{-1}\right)\end{array}$ & $v / U$ & $d_{\mathrm{fl}}$ & $\begin{array}{l}\text { Lacunarity } \\
\text { curve type }\end{array}$ \\
\hline $\begin{array}{l}\text { No clam, } \\
\text { no jet }\end{array}$ & - & - & $\begin{array}{l}0.55 \\
1.20 \\
1.98 \\
2.86\end{array}$ & $\begin{array}{c}-0.08 \pm 0.50 \\
-0.08 \pm 0.67 \\
-0.08 \pm 0.78 \\
0.00 \pm 2.15\end{array}$ & $\begin{array}{r}-0.02 \\
-0.01 \\
0.00 \\
0.00\end{array}$ & $\begin{array}{l}1.80 \\
1.82 \\
1.83 \\
1.87\end{array}$ & $\begin{array}{l}\text { Size } \\
\text { Random } \\
\text { Random } \\
\text { Random }\end{array}$ \\
\hline $\begin{array}{l}\text { Clam shell } \\
(7.0 \mathrm{~cm})\end{array}$ & 0 & - & $\begin{array}{l}0.55 \\
1.20 \\
1.98 \\
2.86\end{array}$ & $\begin{array}{l}0.33 \pm 0.78 \\
0.82 \pm 1.02 \\
1.42 \pm 1.61 \\
2.23 \pm 3.81\end{array}$ & $\begin{array}{l}0.06 \\
0.07 \\
0.07 \\
0.08\end{array}$ & $\begin{array}{l}1.80 \\
1.81 \\
1.76 \\
1.79\end{array}$ & $\begin{array}{l}\text { Random } \\
\text { Random } \\
\text { Random } \\
\text { Random }\end{array}$ \\
\hline Clam mimic & 0.467 & 0.95 & $\begin{array}{l}0.55 \\
1.20 \\
1.98 \\
2.86\end{array}$ & $\begin{array}{c}13.59 \pm 1.25 \\
12.74 \pm 0.61 \\
11.00 \pm 1.51 \\
4.83 \pm 5.65\end{array}$ & $\begin{array}{l}2.47 \\
1.06 \\
0.56 \\
0.17\end{array}$ & $\begin{array}{l}1.52 \\
1.76 \\
1.57 \\
1.92\end{array}$ & $\begin{array}{l}\text { Random } \\
\text { Random } \\
\text { Size } \\
\text { Random }\end{array}$ \\
\hline Clam mimic & 0 & 0.95 & $\begin{array}{l}0.55 \\
1.20 \\
1.98 \\
2.86\end{array}$ & $\begin{array}{l}-3.44 \pm 0.98 \\
-3.50 \pm 1.43 \\
-3.87 \pm 2.02 \\
-4.61 \pm 4.34\end{array}$ & $\begin{array}{l}-0.63 \\
-0.29 \\
-0.20 \\
-0.16\end{array}$ & $\begin{array}{l}1.73 \\
1.83 \\
1.86 \\
1.90\end{array}$ & $\begin{array}{l}\text { Random } \\
\text { Random } \\
\text { Random } \\
\text { Random }\end{array}$ \\
\hline
\end{tabular}

of clams to the density of the clam patch was dependent on the size of the clam (Table 4), and the jet-tocrossflow velocity ratio was larger for smaller clams (Fig. 5b). Therefore, clams had dynamic jet behaviors that were influenced by external conditions, and the result was a change in the unsteady character and distribution of randomness in the velocity of the excurrent jet.

The patterns in the lacunarity curve shapes for the clam jets (Table 4) were not present in the control cases (Table 5). Most notable was the suggestion of dissimilarity in the lacunarity shape patterns between the lacunarity curves for the biological clam jets and the steady clam mimic jets. Steady jet clam mimics or steady chemical sources may not mimic the source characteristics for actual clam chemical metabolite plumes. Therefore, the information available to predators in the downstream plume of a steady source may not necessarily represent the information available to predators in actual clam chemical plumes (see Webster \& Weissburg 2001 for discussion of plume characteristics downstream of steady release sources). The data for the control cases also indicated that there were no contributions to the patterns seen in the lacunarity curve shapes due to the pockets created by the burying action of clams, the presence of the clam shell or non-pumping clams, or the presence of the clam mimic siphon. Finally, since the clam source characteristics were highly unsteady and have lacunarity curve shape patterns that were not seen in steady source clam mimics, studies that use steady clam mimics may be misrepresenting the mixing/dilution of the clam jet. Further, this could impact calculations of concentration boundary layers or clam refiltration rates.

\section{Dominant predator-prey interaction}

The predator-prey system of interest here was the relationship between bivalve clams Mercenaria mercenaria and their predators, knobbed whelks Busycon carica and blue crabs Calinectes sapidus. While both predators use olfactory tracking to locate their clam prey, they have specific consumption methods and are successful in flows possessing different hydrodynamic characteristics. For example, blue crabs prefer to consume smaller, more easily crushed clams, depending on availability and level of starvation (Micheli 1995). In contrast, whelks consume clams of all sizes and have predation success in high turbulence intensity regimes (Ferner \& Weissburg 2005).

There were several clam jet quantities that were significantly different according to the size of the organism. The jet mean vertical velocity was influenced by the bulk mean crossflow velocity (although a pattern is not clear in Table 1), and that influence was dependent on the size of the clam. It should be noted that Price \& Schiebe (1978) found that mean jet velocity values did not vary according to the size of the clam, in contrast to the results of our study. Also, smaller clams were found in our study to have a larger jet-to-crossflow velocity ratio than the larger 
size clams of this experiment (see Fig. 5). Finally, the reaction of the clams to the density of the patch was dependent on the size of the clam, according to the lacunarity curve types (Table 4). This suggests that if the clam behavioral modifications were related to predation, then blue crabs dominate or control the predator-prey system. Since clams of all sizes are susceptible to whelk predation, whelks were not likely controlling the predator-prey relationship here because there was a size dependence on the measured jet excurrent velocities.

Due to the dependence of blue crab predation on ambient turbulence levels, there may be clam feeding strategies that are an attempt to avoid predation by blue crabs that are specific to the clam patch density and the size of the individual organisms. For example, a large chemical plume, resulting from the interaction of many clam excurrent jets, may attract blue crabs to the area, in which case the smallest clams are the most susceptible to predation. On the other hand, since crabs have been shown to react to more discrete filaments of chemical cues (Jackson et al. 2007), it may be advantageous for small clams, when individuals, to employ feeding behavior that avoids predation by controlling the distribution of their jet velocity values.

Blue crabs tend to be more successful at locating prey in regimes with smaller turbulence intensity (unless the flow rate decreases to quiescent), and their success decreases with increasing ambient turbulence (Weissburg \& Zimmer-Faust 1993, Jackson et al. 2007). If blue crab predation pressure is dominating the predator-prey relationship, as the density/size results of this study suggest, then clam behavioral changes according to the ambient turbulence, or in this case, bulk mean crossflow velocity, may also increase survivorship. First, the jet-to-crossflow velocity ratio for the smallest bulk mean crossflow velocity was significantly larger than the ratio at the larger bulk mean crossflow velocity values (Fig. 5). Second, the textural distribution of the clam jet velocity values changed according to the ambient horizontal bulk mean crossflow velocity (Table 4). Hence, as the ambient flow/turbulence regime changed, clams altered the chemical plume source characteristics, which may have been a result of typical predation pressure in those conditions. Weissburg \& Zimmer-Faust (1993) suggested that there may be certain hydrodynamic conditions that provide a refuge from predation by certain predators. A key component for study of the predator-prey system here was how the prey items may disguise their presence within the spatial and temporal environ- ment (Weissburg \& Dusenbery 2002), and our results suggest that clams were altering the randomness of the jet velocities according to the ambient flow and turbulence in a manner that may have contributed to this 'disguise.' However, more information is clearly needed regarding how the behavioral changes actually alter the downstream chemical plumes and the tracking success of predators.

Blue crab tracking success decreases (Keller \& Weissburg 2004) and successful tracks take longer (Page et al. 2011a) when the chemical source plume has a pulsed release rather than a continuous release. The clam jet velocity time records of the current study had highly unsteady velocity values (e.g. Fig. 3), and the lacunarity curves suggested that there were often documented gaps between repeated values of velocity (i.e. 'Size' in Table 4). Therefore, with unsteady clam excurrent jets, as observed here, crabs may have less predation success.

\section{Patch dynamics}

It may be advantageous to be part of a densely packed clam patch when of a certain size range and to be an individual at other size ranges. The difference in clam jet velocity randomness, as found in the current study, was dependent on the density of clams in the patch and the size of the organism (Table 4). There may be a critical clam plot density according to the dominant clam size range within the plot where the excurrent chemical plumes interact with one another and become 1 large plume rather than many individual plumes. Coco et al. (2006) theorized that bivalve patch dynamics were not necessarily the sum of the behaviors of individual animals. The results here suggest that individual clams had specific behaviors for their size and patch density.

Alternatively to predator-prey interactions, the behavior of clams according to the clam density and clam size found herein (Table 4) may not be directly related to predation, but rather indirectly through larval recruitment. Hart et al. (1996) found that larval settlement was highly dependent on hydrodynamic cues. Adult clam feeding behavior may have contributed to those hydrodynamic conditions as a means of communication to larvae as to whether the patch was recruiting or deterring new patch members. The results here indicated that clams of different sizes altered their feeding behavior depending on the density within the patch. If patch recruitment is more dominant than predation pressure, as Coco et al. (2006) suggested, then the differences in feeding 
behavior may not have been fostering a refuge from predation but rather signaling clam larvae or promoting the hydrodynamic conditions that induce or deter larvae from settling. Through this hydrodynamic signaling method, clams of certain sizes may control the clam patch density.

\section{Experimental methods}

The clams used in this study were pumping in a manner that appeared consistent with observations of previous studies. The measurements of Frank et al. (2008) and the extensive testing of seeding particles in this study indicated that titanium dioxide particles passed through Mercenaria mercenaria with sufficient density to facilitate PIV measurements and did not visibly alter the pumping behavior. Troost et al. (2009) used a PIV system to measure the incurrent velocities and modeled the excurrent jet velocities of 3 bivalves: a mussel, an oyster, and a cockle. They were unable to use the PIV system to determine excurrent jet characteristics due to the filter-feeding nature of the organisms who removed the suspended synthetic particles. They predicted excurrent jet velocity values an order of magnitude larger than those collected for clams in the present study, although similar in magnitude to Price \& Schiebe (1978). Frank et al. (2008) found PIV systems to accurately characterize the excurrent jet flow of Mercenaria mercenaria along with an ascidian, a mussel, an oyster, and a scallop. They found similar mean jet velocity values as those collected in the current study without disturbing either the fluid or the animal in quiescent flow conditions. Further, occurrences of 'resting periods' in our study were comparable to those observed by de Bruin \& Davids (1970), which indicates that the presence of the seeding particles and laser sheet were not the cause of the resting periods.

\section{Influence of siphon flow on the plume}

The jet-to-crossflow velocity ratios varied according to the bulk mean crossflow velocity and the size of the organism (Fig. 5). Morton \& Ibbetson (1996) studied jets-in-crossflow with a large range of Reynolds numbers (both laminar and turbulent) for the jet flow and the bulk mean crossflow, and a large range of jet-to-crossflow velocity ratios (1 to 100). They found that the jet-to-crossflow velocity ratio was the most influential factor in the structure of the jet/crossflow interaction. The jet-to-crossflow ratio determined the dominance of structures such as the counter rotating vortex pair, the horseshoe vortices, the wake vortices, and the shear layer vortices. All flows, i.e. laminar and turbulent jets and boundary layers, contain these structures, and the dominance of the structures is dependent on the jet-to-crossflow velocity value (Morton \& Ibbetson 1996).

The jet-to-crossflow velocity ratios were larger for small clams compared to those of the larger clams. This suggested that excurrent jets for small clams were more erect and the bulk mean crossflow had more of a tendency to deflect around the jet (Andreopoulos \& Rodi 1984), the wake vortices were more dominant than the shear layer vortices (Fric \& Roshko 1994, Meyer et al. 2007), and the counter-rotating vortex pair was more dominant than the horseshoe vortices (Jabbal \& Zhong 2008, Sau \& Mahesh 2008). In contrast, excurrent jets for the larger clams were more severely bent over and the bulk mean crossflow tended to deflect over the jet (Andreopoulos \& Rodi 1984, Demuren 1992, 1993), the shear layer vortices were more dominant with respect to the wake vortices (Fric \& Roshko 1994, Meyer et al. 2007), and the hairpin vortices were more dominant with respect to the counter rotating vortex pair (Jabbal \& Zhong 2008, Sau \& Mahesh 2008).

We also found that at the smallest bulk mean crossflow velocity, the jet-to-crossflow velocity ratio was larger than the other bulk mean crossflow velocities used here. In this small bulk mean crossflow velocity case, the jet-to-crossflow velocity ratio indicated dominance of the counter rotating vortex pair (Sau \& Mahesh 2008), dominance of the wake vortices (Fric \& Roshko 1994, Meyer et al. 2007), and a more erect jet with bulk mean crossflow deflecting around the jet (Andreopoulos \& Rodi 1984).

The clam jet velocity time records presented here were highly unsteady (Fig. 3), and the character of the unsteadiness changed with horizontal crossflow velocity and size and density of clams (Table 4). While the velocity time records of the clams did not necessarily have specific pulsing frequencies associated with them, we can compare the time records to literature quantifying the effects of pulsed jets and pulsed jets-in-crossflow due to the unsteady nature of pulsed jet flow. Bera et al. (2001) found that unsteady (pulsed) jets have greater rates of entrainment of the receiving fluid into the jet when compared to steady jets. The larger rates of entrainment resulted in smaller concentrations of the jet fluid in the plume. For clams, this may result in the dilution of chemical metabolites, and it may be advantageous to encourage the mixing of the chemical plume. 
Plumes from laminar pulsed jets have increased spread compared to continuous jets, and laminar vortex rings are more persistent due to the unsteadiness (Cater \& Soria 2002). As vortex rings are more persistent, they are present longer and travel higher in the water column before they are dissipated, resulting in more entrainment of the ambient fluid.

In summary, knowledge about jets-in-crossflow provided some insight to the flow structure, mixing, and entrainment characteristics of the excurrent flow. This information provided some explanation of the observed behavior differences. Nevertheless, questions remain about the details of the mixing characteristics.

Acknowledgements. We thank M. J. Weissburg for helpful suggestions and use of his seawater flume. Thanks also to the National Science Foundation for financial support under grants OCE-0424673 to M. J. Weissburg and D.R.W. and for an NSF IGERT fellowship awarded to S.K.D.

\section{LITERATURE CITED}

Allain C, Cloitre M (1991) Characterizing the lacunarity of random and deterministic fractal sets. Phys Rev 44: 3552-3558

Andreopoulos J, Rodi W (1984) Experimental investigation of jets in a crossflow. J Fluid Mech 138:93-127

> Bera JC, Michard M, Grosjean N, Comte-Bellot G (2001) Flow analysis of two-dimensional pulsed jets by particle image velocimetry. Exp Fluids 31:519-532

> Cater JE, Soria J (2002) The evolution of round zeronet-mass-flux jets. J Fluid Mech 472:167-200

> Catton KB, Webster DR, Brown J, Yen J (2007) Quantitative analysis of tethered and free-swimming copepodid flow fields. J Exp Biol 210:299-310

$>$ Coco G, Thrush SF, Green MO, Hewitt JE (2006) Feedbacks between bivalve density, flow, and suspended sediment concentration on patch stable states. Ecology 87: $2862-2870$

> Crimaldi JP, Koseff JR, Monismith SG (2007) Structure of mass and momentum fields over a model aggregation of benthic filter feeders. Biogeosciences 4:269-282

Dasi LP (2004) The small-scale structure of passive scalar mixing in turbulent boundary layers. PhD thesis, Georgia Institute of Technology, Atlanta, GA

de Bruin JPC, Davids C (1970) Observations on the rate of water pumping of the freshwater mussel Anodonta cygnea zellensis (Gmelin). Neth J Zool 20:380-391

Demuren AO (1992) Multigrid acceleration and turbulence models for computations of 3D turbulent jets in crossflow. Int J Heat Mass Transfer 35:2783-2794

$>$ Demuren AO (1993) Characteristics of three-dimensional turbulent jets in crossflow. Int J Eng Sci 31:899-913

Fan LT, Neogi D, Yashima M, Nassar R (1990) Stochastic analysis of a three-phase fluidized bed: fractal approach. AIChE J 36:1529-1535

Ferner MC, Weissburg MJ (2005) Slow-moving predatory gastropods track prey odors in fast and turbulent flow. J Exp Biol 208:809-819

Frank DM, Ward JE, Shumway SE, Holohan BA, Gray C
(2008) Application of particle image velocimetry to the study of suspension feeding in marine invertebrates. Mar Freshw Behav Physiol 41:1-18

Fric TF, Roshko A (1994) Vortical structure in the wake of a transverse jet. J Fluid Mech 279:1-47

Gui L, Wereley ST (2002) A correlation-based continuous window-shift technique to reduce the peak-locking effect in digital PIV image evaluation. Exp Fluids 32: 506-517

> Hart DD, Clark BD, Jasentuliyana A (1996) Fine-scale field measurement of benthic flow environments inhabited by stream invertebrates. Limnol Oceanogr 41:297-308

Hurst HE, Black RP, Simaika YM (1947) A long-term plan for the Nile basin. Nature 160:611-612

> Jabbal M, Zhong S (2008) The near wall effect of synthetic jets in a boundary layer. Int $\mathrm{J}$ Heat Fluid Flow 29: $119-130$

- Jackson JL, Webster DR, Rahman S, Weissburg MJ (2007) Bed-roughness effects on boundary-layer turbulence and consequences for odor-tracking behavior of blue crabs (Callinectes sapidus). Limnol Oceanogr 52:1883-1897

$>$ Keller TA, Weissburg MJ (2004) Effects of odor flux and pulse rate on chemosensory tracking in turbulent odor plumes by the blue crab, Callinectes sapidus. Biol Bull (Woods Hole) 207:44-55

Kindsvater CE, Carter RWC (1957) Discharge characteristics of rectangular thin-plate weirs. J Hydraul Div 83: $1453-1488$

Mandelbrot BB, Van Ness JW (1968) Fractional Brownian motions, fractional noises and applications. SIAM Rev 10:422-437

> Mead KS, Koehl MAR (2000) Stomatapod antennule design: the asymmetry, sampling efficiency and ontogeny of olfactory flicking. J Exp Biol 203:3795-3808

> Meyer KE, Pedersen JM, Özcan O (2007) A turbulent jet in crossflow analysed with proper orthogonal decomposition. J Fluid Mech 583:199-227

> Micheli F (1995) Behavioural plasticity in prey-size selectivity of the blue crab Callinectes sapidus feeding on bivalve prey. J Anim Ecol 64:63-74

Monismith SG, Koseff JR, Thompson JK, O'Riordan CA, Nepf HM (1990) A study of model bivalve siphonal currents. Limnol Oceanogr 35:680-696

Morton BR, Ibbetson A (1996) Jets deflected in a crossflow. Exp Therm Fluid Sci 12:112-133

O'Riordan CA (1993) The effects of near-bed hydrodynamics on benthic bivalve filtration rates. PhD thesis, Stanford University, Palo Alto, CA

Page JL, Dickman BD, Webster DR, Weissburg MJ (2011a) Getting ahead: context-dependent responses to odor filaments drive along-stream progress during odor tracking in blue crabs. J Exp Biol 214:1498-1512

> Page JL, Dickman BD, Webster DR, Weissburg MJ (2011b) Staying the course: chemical signal spatial properties and concentration mediate cross-stream motion in turbulent plumes. J Exp Biol 214:1513-1522

Peng J, Dabiri JO, Madden PG, Lauder GV (2007) Noninvasive measurement of instantaneous forces during aquatic locomotion: a case study of the bluegill sunfish pectoral fin. J Exp Biol 210:685-698

Plotnick RE, Gardner RH, Hargrove WW, Prestegaard K, Perlmutter M (1996) Lacunarity analysis: a general technique for the analysis of spatial patterns. Phys Rev 53:5461-5468

Price RE, Schiebe FR (1978) Measurements of velocity from 
excurrent siphons of freshwater clams. Nautilus 92: 67-69

Sau R, Mahesh K (2008) Dynamics and mixing of vortex rings in crossflow. J Fluid Mech 604:389-409

Smee DL, Weissburg MJ (2006) Clamming up: environmental forces diminish the perceptive ability of bivalve prey. Ecology 87:1587-1598

Tammes PML, Dral ADG (1956) Observations on the straining of suspensions by mussels. Arch Neerl Zool 11:87-112

Tolle CR, McJunkin TR, Gorsich DJ (2008) An efficient implementation of the gliding box lacunarity algorithm. Physica D 237:306-315

Troost K, Stamhuis EJ, van Duren LA, Wolff WJ (2009) Feeding current characteristics of three morphologically different bivalve suspension feeders, Crassostrea gigas, Mytilus edulis and Cerastoderma edule, in relation to food competition. Mar Biol 156:355-372

van Duren LA, Herman PMJ, Sandee AJJ, Heip CHR (2006) Effects of mussel filtering activity on boundary layer

Editorial responsibility: Peter Beninger,

Nantes, France structure. J Sea Res 55:3-14

> Webster DR, Weissburg MJ (2001) Chemosensory guidance cues in a turbulent chemical odor plume. Limnol Oceanogr 46:1034-1047

Weiss DJ (2009) Nominal analysis of 'variance'. Behav Res Methods 41:901-908

> Weissburg MJ, Dusenbery DB (2002) Behavioral observations and computer simulations of blue crab movement to a chemical source in a controlled turbulent flow. J Exp Biol 205:3387-3398

Weissburg MJ, Zimmer-Faust RK (1993) Life and death in moving fluids: hydrodynamic effects on chemosensorymediated predation. Ecology 74:1428-1443

Wereley ST, Meinhart CD (2001) Second-order accurate particle image velocimetry. Exp Fluids 31:258-268

Wilson ML (2011) Sensory landscape impacts on odormediated predator-prey interactions at multiple spatial scales in salt marsh communities. PhD thesis, Georgia Institute of Technology, Atlanta, GA

Submitted: October 5, 2010; Accepted: June 22, 2011 Proofs received from author(s): August 29, 2011 